\title{
New Insights in the Properties of Cellulose in Phosphoric Acid: Viscometric Study
}

\author{
Mohamed Ramzi ${ }^{*}$, Gert Jan Vroege and Hendrik N.W. Lekkerkerker \\ Van't Hoff Laboratory for Physical and Colloid Chemistry, \\ Debye Institute, Utrecht University, Padualaan 8, 3584 CH Utrecht, \\ Netherlands.
}

SUMMARY: Measurements of viscosity were carried out using several solutions of cellulose in different concentrations of phosphoric acid at different temperatures. The intrinsic viscosity $[\eta]_{0}$, a measure for the size of a single chain and the Huggins constant $\mathrm{k}_{\mathrm{H}}$, a measure for the interaction between chains were derived.

\section{Introduction}

A certain number of polymers and biopolymers form an anisotropic phase above a certain concentration and in appropriate solvents. This phenomenon has been explained theoretically ${ }^{1-3)}$ and observed experimentally in different systems. It was shown that the anisotropic solutions could be obtained with concentrated solutions of semi-rigid polymers such as cellulose and cellulose derivatives ${ }^{4-5)}$.

Despite the progress made, not all liquid crystalline polymers are yet studied and fully understood theoretically. Liquid crystalline polymers can be approached theoretically with the basic model that of rigid $\operatorname{rod}^{1-3)}$. However, the molecules are often semi-rigid or contain flexible spacers between the rigid groups which introduces more possibilities for the configuration ${ }^{6}$.

Besides the chain stiffness, the polymer-solvent interaction plays an important role for the formation of an ordered liquid crystalline phase: ethyl cellulose forms a mesophase in 1,4-dioxane and an isotropic gel in butylacetate despite comparable chain stiffness ${ }^{7)}$. And it should be noted that the flexibility of the polymer backbone of various, similar cellulose derivatives depends to some extent on the type of solvent used $^{8)}$.

The systems of interest here consist of cellulose in phosphoric acid (PA) which is a cheap solvent for cellulose and compared to other solvents, relatively friendly for the environment. One of the important properties of cellulose solutions in phosphoric acid is the formation of a liquid crystalline phase at high concentration above $8 \% \mathrm{w} / \mathrm{w}^{9-10)}$, which also stimulates the dissolution process. It has been suggested that the formation 
of hydrates and solvates of phosphoric acid as a first step in the interaction may explain the solubility of cellulose in concentrated solutions of phosphoric acid ${ }^{11-13)}$. We have two motivations to investigate the cellulose/PA system:

1) To study the mesophase formation from a scientific viewpoint for this polymer intermediate between flexible polymers and typical stiff polymers and understand why it gives a mesophase at concentrations typical for stiff polymers.

2) To examine the formation of liquid-crystal from a technological viewpoint for example for higher modulus regenerated cellulose fiber.

In our present investigation, we present viscosity data for dilute solutions of cellulose in phosphoric acid. A knowledge of how cellulose and phosphoric acid interact under the influence of varying PA concentrations and the temperature will help in discovering the mechanisms giving rise to the liquid crystallinity in concentrated solutions.

\section{Experimental Section}

Materials. The cellulose sample (Buckeye V60) used in this study was kindly supplied by Akzo Nobel. The molecular weight distribution of the sample is $\mathrm{M}_{\mathrm{w}} / \mathrm{M}_{\mathrm{n}} \sim 2.5$, with $\mathrm{M}_{\mathrm{w}}=1.38 \times 10^{5}, \mathrm{M}_{\mathrm{n}}=5.54 \times 10^{4}$. The degree of polymerization was informed to be 855 .

Phosphoric acid of varying $\mathrm{P}_{2} \mathrm{O}_{5}$ content below $74.3 \%$ was prepared by mixing $61.6 \%$ $\mathrm{P}_{2} \mathrm{O}_{5}$ (85\% Phosphoric acid) purchased from Merck and 74.3\% $\mathrm{P}_{2} \mathrm{O}_{5}$ provided and characterized by Akzo Nobel. Higher $\mathrm{P}_{2} \mathrm{O}_{5}$ content was obtained by mixing pure phosphorus pentoxide $\left(98 \% \mathrm{P}_{2} \mathrm{O}_{5}\right)$ with water or by mixing $74.3 \% \mathrm{P}_{2} \mathrm{O}_{5}$ with polyphosphoric acid $\left(85.3 \% \mathrm{P}_{2} \mathrm{O}_{5}\right)$, purchased from Aldrich.

Sample Preparation. To prepare the dilute solutions for the viscosity experiments, a polymer stock solution at $\mathrm{C}=1 \%(\mathrm{w} / \mathrm{w})$ was made. Holding the solution in an ice bath during the preparation, helps the homogenising by increasing the viscosity of the solvent and also slows down the hydrolysis of cellulose. After preparation, the solution was centrifuged for 20 minutes at $2500 \mathrm{rot}$. $/ \mathrm{min}$ in order to remove a very small amount of the insoluble component, the resulting small systematic error in the 
concentration is of no consequence. To avoid the decomposition of the polymer, the solution has to be kept at low temperature before the measurements $\left(\sim 4^{\circ} \mathrm{C}\right)$. All the experiments were done with the freshly made solution to avoid (or minimise) the degradation of cellulose chains.

Rheometer. Viscometry is still extensively used in many investigations of polymers and biopolymers in solution because of its technical simplicity and extreme sensitivity. The experiments were carried out on a Bohlin VOR rheometer using a cylinder set up. The viscosity of cellulose solutions was measured at shear rates below the value of shear thinning, varying with the cellulose concentration and the solvent quality. The concentration dependence of the viscosity was measured at four temperatures $5,10,15$ and $20 \pm 0.1^{\circ} \mathrm{C}$. The instrument was calibrated using an oil of a known viscosity $\left(53.68 \mathrm{mPa} . \mathrm{s}\right.$ at $\left.20^{\circ} \mathrm{C}\right)$.

\section{Theoretical Analyses}

The specific viscosity of a polymer solution can be written as:

$\eta_{s p}=\frac{\eta}{\eta_{0}}-1$

And the reduced viscosity is :

$\frac{\eta_{s p}}{C}=\frac{\eta-\eta_{0}}{\eta_{0} C}$

where $\eta$ is the viscosity of the solution of polymer concentration $C$ and $\eta_{0}$ is the viscosity of pure solvent.

According to the Huggins equation :

$\frac{\eta_{s p}}{C}=\frac{\eta-\eta_{0}}{\eta_{0} C}=[\eta]_{0}+k_{H}[\eta]_{0}^{2} C$

where $[\eta]_{0}$ is the intrinsic viscosity of the solution, which is proportional to the hydrodynamic volume of a gram of individual non interacting chains.

Plots of $\left(\eta-\eta_{0}\right) / \eta_{0} \mathrm{C}$ versus $\mathrm{C}$ are usually linear at low concentration (dilute solution), and the slopes of these plots are found to vary with solvent quality; $\mathrm{k}_{\mathrm{H}}$ is known as the Huggins constant. Experimentally, $\mathrm{k}_{\mathrm{H}}$ is independent of the molecular weight for long 
chains, but dependent on the polymer, the temperature and the solvent nature, with values of roughly 0.30 to 0.40 in good solvents and 0.50 to 0.80 in theta solvents ${ }^{14)}$.

\section{Results and discussion}

In order to determine the intrinsic viscosity of cellulose in phosphoric acid (PA), the viscosity of the solution, $\eta$, and that of the solvent, $\eta_{s}$, were measured as a function of cellulose concentration. Fig. 1 shows a typical data set of the viscosity of a dilute

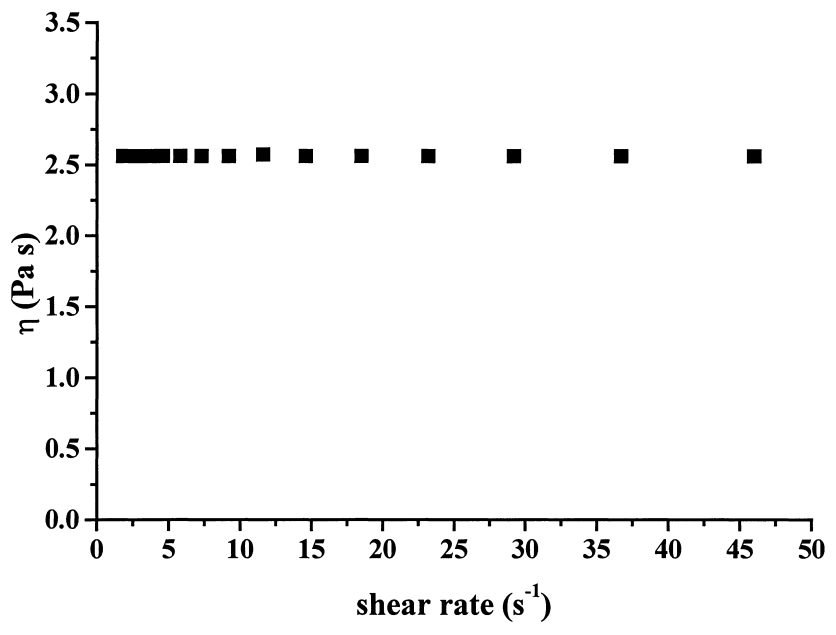

Fig.1: Set of the viscosity of cellulose $\mathrm{C}=0.178 \%(\mathrm{~g} / \mathrm{ml})$ in $76 \% \mathrm{P}_{2} \mathrm{O}_{5}$ as a function of shear rate

cellulose solution in $76 \% \mathrm{P}_{2} \mathrm{O}_{5}$. No shear rate dependence is observed. Similar data sets were collected for pure solvent. The reduced specific viscosity $\eta_{\mathrm{sp}} / \mathrm{C}$ vs. concentration of cellulose $\mathrm{C}$, displayed in Fig.2, shows a linear dependence between $\eta_{\mathrm{sp}} / \mathrm{C}$ and $\mathrm{C}$ in the whole range of concentration. By extrapolation of $\eta_{\mathrm{sp}} / \mathrm{C}$ to zero concentration, the intrinsic viscosity $[\eta]_{0}$ can be obtained. The values of $[\eta]_{0}$ and the Huggins coefficients $\mathrm{k}_{\mathrm{H}}$ are given in Tab.1. As can be seen the values of [ $\left.\eta\right]_{0}$ are in the same range as those found for cellulose and cellulose derivatives ${ }^{15)}$. The high values of $\mathrm{k}_{\mathrm{H}}$ may be explained by the effect of the concentration dependent association between 
cellulose chains. This association is expected to have additional effect on the viscosity. Morawetz found in the case of an acid copolymer a high value of $\mathrm{k}_{\mathrm{H}}$ about $2.3^{16}$ ) indicating a strong interaction between the solvent and the acid copolymer.

Table 1. Intrinsic viscosity and Huggins coefficients of cellulose in different $\mathrm{P}_{2} \mathrm{O}_{5}$ concentrations and at two temperatures.

\begin{tabular}{|c|c|c|c|c|}
\hline \multirow[t]{2}{*}{$\mathrm{T} /{ }^{\circ} \mathrm{C}$} & \multicolumn{4}{|c|}{$\% \mathrm{P}_{2} \mathrm{O}_{5}$} \\
\hline & 73 & 74.3 & 75 & 76 \\
\hline $5^{\circ} \mathrm{C}$ & $\begin{array}{l}{[\eta]_{0}=308 \mathrm{ml} / \mathrm{g}} \\
\mathrm{k}_{\mathrm{H}}=2.26\end{array}$ & $\begin{array}{l}{[\eta]_{0}=384 \mathrm{ml} / \mathrm{g}} \\
\mathrm{k}_{\mathrm{H}}=1.53\end{array}$ & $\begin{array}{l}{[\eta]_{0}=419 \mathrm{ml} / \mathrm{g}} \\
\mathrm{k}_{\mathrm{H}}=1.29\end{array}$ & $\begin{array}{l}{[\eta]_{0}=474 \mathrm{ml} / \mathrm{g}} \\
\mathrm{k}_{\mathrm{H}}=1\end{array}$ \\
\hline $20^{\circ} \mathrm{C}$ & $\begin{array}{l}{[\eta]_{0}=222 \mathrm{ml} / \mathrm{g}} \\
\mathrm{k}_{\mathrm{H}}=2.78\end{array}$ & $\begin{array}{l}{[\eta]_{0}=285 \mathrm{ml} / \mathrm{g}} \\
\mathrm{k}_{\mathrm{H}}=2.4\end{array}$ & $\begin{array}{l}{[\eta]_{0}=294 \mathrm{ml} / \mathrm{g}} \\
\mathrm{k}_{\mathrm{H}}=1.97\end{array}$ & $\begin{array}{l}{[\eta]_{0}=303 \mathrm{ml} / \mathrm{g}} \\
\mathrm{k}_{\mathrm{H}}=1.65\end{array}$ \\
\hline
\end{tabular}

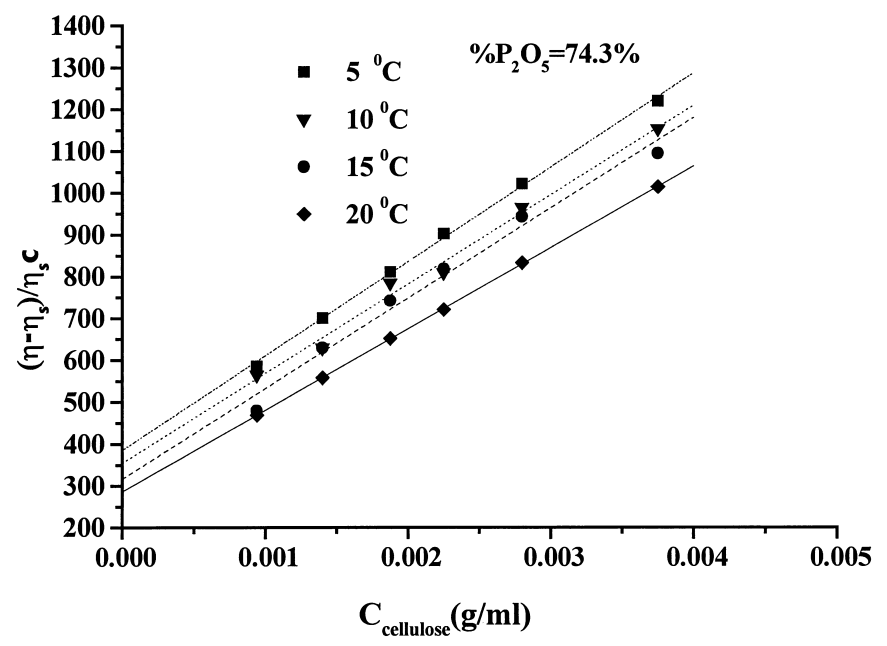

Fig.2: The reduced viscosity as a function of the cellulose concentration at different temperatures. 
Fig. 3 shows the plot of the temperature dependence of the intrinsic viscosity. It can be seen that $[\eta]_{0}$ decreases on increasing the temperature. Indicating that the polymer molecules are considerably expanded at low temperature and shrink upon heating. This behavior is due to an increasing extent of inter-segment interactions, resulting from the decreasing solvent power. The solvent becomes less good at higher temperature, which can probably also explain the increase of $\mathrm{k}_{\mathrm{H}}$ with temperature.

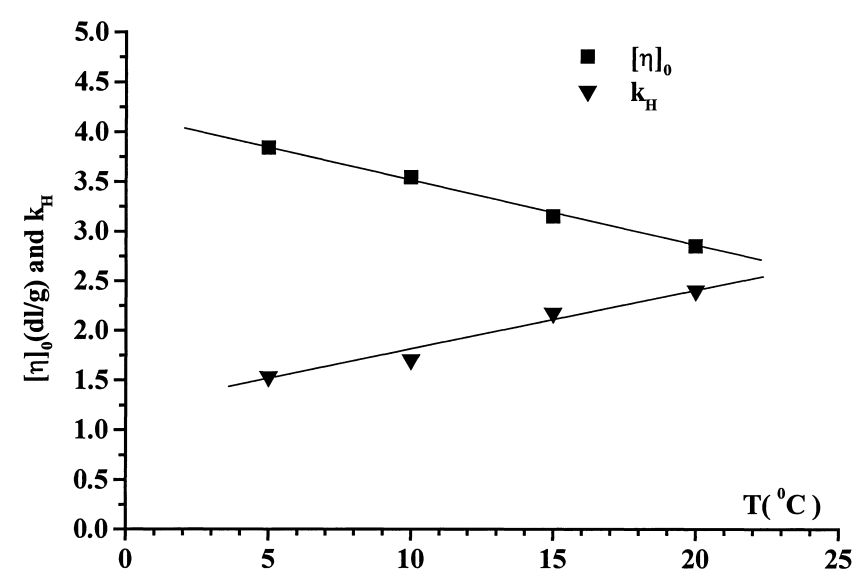

Fig.3: The intrinsic viscosity and Huggins coefficients derived from Fig.2 as a function of temperature.

As pointed out by Tanford ${ }^{17)}$, the intrinsic viscosity of a rigid polymer should be essentially independent of temperature. In our case the decrease of the intrinsic viscosity with increasing temperature indicates that cellulose in phosphoric acid is not a perfectly stiff molecule in the considered range of temperature, and the lower the temperature is the more stiff the cellulose molecules are.

\section{Conclusion}

From viscosity measurements it turns out that very dilute solutions in which we expect isolated chains, show signs of concentration dependent association of chains. This 
behavior suggests that PA is only a marginal solvent, as chain-chain contacts are favoured. PA becomes a better solvent upon decreasing the temperature. The viscosity experiments certainly show that solutions of cellulose in PA do not behave in the classical way.

\section{Acknowledgement}

The work was performed under financial support from the Ministry of Economic Affairs through the Economy, Ecology and Technology (EET) program.

\section{References}

1. L. Onsager, Ann. N.Y. Acad. Sci. 51, 627 (1949)

2. A Isihara, J. Chem. Phys., 19, 1142 (1951)

3. P.J. Flory, Proc. R. Soc. London, Ser. A, 234, 73 (1956)

4. R.S. Werbowji and D.G. Gray, Macromolecules, 13, 69 (1980)

5. D. L. Patel and R, D. Gilbert, J. Polym. Sci., Polym. Phys. Ed., 19, 1231 (1981)

6. A.R. Khokhlov and A.N. Semenov, Physica A, 108, 546 (1981)

7. D. G. Gray, B. R. Harkness, in Liquid Crystalline and Mesomorphic Polymers, eds.V.P. Shibaev,

L. Lam, Springer Verlag, New York, pp. 298 (1994)

8. K. Kamide, Makromol. Chem., Makromol. Symp., 83, 233 (1994)

9. R.D.Gilbert, Int. Fibre Sci. Technol. Ser.12, Vol.3, 357 (1993)

10. H. Boerstoel, "Liquid Crystalline Solutions of Cellulose in Phosphoric Acid", Ph.D thesis, Groningen (1998)

11. S. U. Hadson and D. A. Cuculo, J. Macromol. Sci. Rev. Macromol. Ch., C18(1), $\mathrm{N}^{0} 1,3$ (1980)

12. V. A Elkin, in : Chemistry and Technology of Cellulose, Izd-vo LGU, Leningrad P. 75 (1974)

13. S. V. Bleshinskii, The Salting of Organic Substances, ILIM, Frunze (1967)

14. Polymer Handbook, J. Brandrup and E.H. Immergut, Eds., Wiley, New York (1975)

15. J.M.Peterson and M. Fixman, J. Chem. Phys. 39, 2516 (1963)

16. H. Morawetz, ind. Chim. Belg. 19, 607 (1954)

17. C. Tanford, Physical Chemistry of Macromolecules, Wiley, New York (1961) 
